\title{
The Role of the Teacher in Primary School Web 2.0 Use
}

\author{
Joanne Blannin \\ University of Melbourne, Australia
}

\begin{abstract}
Information and communication technologies (ICTS) have become ubiquitous in our society. In particular, 10-12 year old (primary school aged) children report that they increasingly rely upon ICTs for social interaction and for learning (ACMA, 2013). In spite of the large number of students reporting high ICT use, research indicates that many primary school teachers are not making effective use of online resources in the classroom. Influencing this lower level use is a lack of specifically focused research that considers the vital role of the primary school teacher in the integration of ICTs into the classroom program. To identify where research is most needed and might be most useful to support teachers to increase the use of ICTs in the classroom, this paper draws on research conducted in primary, secondary and tertiary education. It defines three core areas in which research is needed. These areas are teachers' internal (personal) and external (socio-cultural) barriers as well as the students' role in, and expectations of, pedagogical changes to classroom learning.
\end{abstract}

Keywords: Online learning; Self-efficacy; Teacher professional learning; Primary schooling; ICT integration; Increasing ICT use.

\section{Introduction}

There is increasing concern that the effective use of Information and Communication Technologies (ICTs) in primary schooling has not yet received the research focus necessary for deeper integration of ICTs to occur (White, 2008a). In particular, research considering the unique setting of the primary school continues to be scarce (Jimoyiannis, Tsiotakis, Roussinos, \& Siorenta, 2013; Means, Toyama, Murphy, Bakia, \& Jones, 2009) and this lack of research is limiting the sources to which school teachers and leaders can refer to for examples of effective use. It is this limited research that is the focus of this paper, the outcome of which suggests that research focus should be given to the impact of the teacher as leader in the classroom and to the students themselves, rather than explicitly on ICTs and their usage as is often seen in current research.

The number and scope of ICTs is vast and ever expanding; this paper cannot focus on all available resources. There is, however, one sub-section of ICTs that appears to be growing very quickly within schools, and which has also received limited research focus. It is variously referred to as Web 2.0 (Alexander \& Levine, 2008), the Social Web (White, 2008b), the Personal Web (Drexler, 2010) or the Interactive Web (Kay \& Knaack, 2008). These online environments support student-to-student and teacher-to-student interaction, with most descriptions of Web 2.0 referring to online resources that offer opportunities for creativity, collaboration and communication. Resources that offer these three key opportunities include learning management systems, online classrooms and cloud-based storage and are becoming 
increasingly popular in primary schools. Web 2.0 resources may offer innovative teaching opportunities but they also require many teachers to change the way they plan, interact and deliver content to their students. Indeed, as more and more Web 2.0 resources, websites and online tools become available, Crook, Cummings et al. (2008) predict that the role of the teacher will increasingly become taking content-free online tools and using their existing pedagogical skills to create online content and learning experiences for the benefit of each individual learner. With the changes to pedagogy these resources appear to require, and with consideration of the rapid growth in their use in schools, this paper has focused on the effective use of Web 2.0 resources (rather than ICTs as a whole), considering the role of the teacher and the student in the use of Web 2.0 for learning and teaching.

It must be noted that there are other research papers that focus on Web 2.0 use that may be useful in supporting primary school teachers and leaders. However much of this research focuses on secondary and tertiary education settings. Significant challenges exist with the transferability of these findings into primary school classrooms, (Lincoln \& Guba, 1985; Patton, 2001) as the primary school setting, the teachers' role and relationship with their students is quite different. Younger students require more online support and training in the safe and effective use of Web 2.0 than their older, more independent counterparts. Indeed many online Web 2.0 resources are not available for students to use until they reach 13 years of age. These challenges imply that we cannot assume that research carried out with older (possibly adult) students can be transferred to the primary classroom. For the purposes of this paper, research focused on secondary and tertiary learning has informed the claims of specific areas needed to support Web 2.0 use in the primary classroom, but consideration has also been made of the different contexts within which primary school teachers and students work and learn.

The paper that follows begins with a perspective on the Australian context for the promotion of ICT use in schools. The paper then considers the role of the teacher and the student in the use of Web 2.0 for learning. This includes a consideration of the factors influencing teachers' use of Web 2.0 resources, both internal (personal) and external (socio-cultural) factors. The paper next reflects on the expectations and readiness of students to make use of Web 2.0 for their learning. This paper concludes with a summary of the major areas in which research might better support the integration of Web 2.0 resources into primary schools and the overall implications of this review for the educational use of ICTs in general.

\section{Global and National Focus on the Use of Web 2.0}

Educational use of ICT in Australia has a long history and is influenced by both political and societal pressures. One example of this is the national declaration that all Australian students need to be "highly skilled in the use of ICT" (Ministerial Council on Education Employment Training and Youth Affairs, 2008 p. 5). There are many global changes in education that continue to seep across borders towards and into Australia. These "mono-cultural logics" (Santos 2003, in Apple, 2010, p. 1), referring to the homogenization of disparate cultures and education systems, continue to develop around what education is and should be within Australia (Collins, 2010). Australia's policies and educational systems continue to be influenced by the educational policies, expectations and experiences of other developed and developing nations to whom we are connected. 
This connectedness situates Australia as a member of an evolving global partner in changing education systems, within which technology plays an integral role. For example, in the state of Victoria the Department of Education and Early Childhood Development (DEECD, 2012, p.1) claims that Web 2.0 resources offer positive learning experiences and are promoted as tools that "allow for rich use" and "provide rich opportunities" for learning. At a national level, the Australian Digital Education Advisory Group (DEAG) (2013 p. 10) recommended, "governments develop and disseminate strategies to engage and support the whole community in digital education", thereby focusing on the wider national and international benefits of the use of ICT in education.

Within Australia, the recent move towards a national curriculum has also seen ICT use identified as a significant 'general capability' for students, as well as a specific content learning area. The Australian Curriculum and Assessment Authority, have identified that:

"Australia needs enterprising individuals who can make discerning decisions about the development and use of technologies and who can independently and collaboratively develop solutions to complex challenges and contribute to sustainable patterns of living." ("Australian Curriculum: Overview General Capabilities ", 2014).

The development of ICT skills, within this new curriculum, is not confined to the content area of 'Technologies'. As a 'general capability', teachers are directed to make use of technologies across all content areas:

"Across the Australian Curriculum, students develop ICT capability as they learn to use ICT effectively and appropriately to access, create and communicate information and ideas, solve problems and work collaboratively, and in their lives beyond school." ("Australian Curriculum: Overview General Capabilities ", 2014)

Within the state of Victoria, moves to more formally embrace these national and global priorities are seen in the development of the Towards Victoria as a Learning Community (TVLC) program (Communications Division for Flagship Strategies Division, 2012). The TVLC position paper states: "Education drives growth, productivity and global competitive advantage" (Communications Division for Flagship Strategies Division, 2012, p. 2), clearly positioning Victorian education within national and global contexts as a driving force in raising national economic and educational competiveness.

These national and Victorian declarations position classroom teachers as leaders in achieving these national goals, as they make decisions about when, how and whether to use ICTs in their classrooms. Education systems are led and driven by these individuals who hold disparate values and beliefs about education, its role in society and the role of educators (Chen, 2008). As Chen (2008 p. 65) remarks, "To implement national plans for technology integration, policymakers must know how teachers' beliefs influence teachers' practices regarding technology integration." The role of the teacher in the effective use of ICTs is therefore of paramount importance for the future of education in Australia.

\section{Internal Factors Impacting on Teachers' Use of Web 2.0 Resources}

While global, national and school leaders may have impact on the wider agenda for education, it is the individual teacher who leads primary school students to their learning, either through 
traditional or online resources. Ang and Wang (2006); Doherty (2011), among others, have conducted research into the ways teachers' beliefs and values impact on their choices to use technology in their classrooms. While not focused on the primary school teacher, they highlight key areas relevant to supporting the use of Web 2.0 in primary classrooms. These factors are personal beliefs, personal values and self-efficacy levels.

\section{Teacher Beliefs and Values}

Chen's (2008) case study of 12 high school teachers in Taiwan proposed that teachers do not always act according to their professed beliefs. While the teachers in this study claimed an affiliation with constructivist, student-centered beliefs about teaching, their use of ICT for learning in the classroom did not reflect this. Chen's (2008) study, however, was conducted within the Taiwanese education system that, as Chen notes, had seen a recent shift in policy focus towards constructivist ideals. This may have impacted on teachers' responses, as they aimed to align themselves with the prevalent culture of constructivist thought through their declarations, if not through their actions (Clandinin \& Connelly, 1996).

From this study Chen (2008) concluded that personal beliefs impact a teachers' use of ICT, particularly when those beliefs are influenced by values held by others. As high scoring examination results were prized in the Taiwanese education system teachers were perceived to have focused their teaching to achieve this outcome, rather than on developing constructivist or student-centered learning experiences with ICTs. In Australia, one example of a similar external influence might be the national focus on formal testing (through the National Assessment Program), which may be impacting on teachers' willingness to change their classroom practice. They may believe that their current methods are achieving adequate test scores (the perceived goal of education) and so be less inclined to shift their pedagogical approaches towards more individualized and technology-focused strategies.

In considering the use of Web 2.0 technologies in the classroom, it is therefore important to consider the beliefs that teachers hold around online resources, the use of which can require a change to teaching approach that is more student-centered. As Chen (2008 p. 67) has previously noted, teachers do not often pause to consider their own beliefs around teaching. Chen (2008) goes further to claim that teachers often do not understand the theoretical background and implications of key learning theories, which then impacts on or limits their technology use in the classroom. This lack of understanding, he claims, is the core challenge facing the goal of deeper integration of Web 2.0 into classrooms. Teachers' beliefs about teaching and its purpose may in fact be limited by their understanding of how students learn and how technology might support different kinds of learning.

Through their study into ICT integration Sang, Valcke, Van Braak, and Tondeur (2010) provide evidence that supports Chen's (2008) conclusion, namely that the internal experiences, beliefs and values of a teacher significantly influence their use of ICT in a classroom. Sang et al. (2010, p. 7) go so far as to claim "successful ICT integration is clearly related to the thinking processes of classroom teachers". Their qualitative study analyzed the self-reported attitudes of trainee teachers towards ICT integration and concluded that positive attitudes towards computer use and towards constructivist theory, as well as high levels of self-efficacy were indicators of ability and willingness to integrate ICTs into the classroom setting. Once a teacher is working in a school, however, it is not clear if this willingness is translated into action, this ability to transform beliefs into practice was the subject of a study by Hramiak and Boulton (2013). 
Hramiak and Boulton (2013) study considered the challenges of transferring skills from a teacher-training environment (a PGSE course in the UK) to a classroom setting during a teacher's first year of teaching. The findings were less than encouraging. In spite of a high level of acceptance and the use of blogs during their training, these teachers found that using these skills in their new, professional setting was not easy, diminishing, perhaps, the optimistic belief that future teachers may be able to impact positively on ICT use in schools. A lack of support from more experienced school leaders at the workplace, a lack of access to technology or appropriate facilities as well as a lack of time to embed these practices were identified as the main barriers to the educational use of ICTs and Web 2.0 (Hramiak \& Boulton, 2013). This indicates that there are many complex factors that impact on the educational use of technologies, beyond the teacher themselves or even the provision of hardware for teaching and learning.

While Hramiak and Boulton (2013), Martin and Noakes (2012) and Fu (2013) support Chen (2008) in highlighting the significance of teachers' beliefs they also point to the potential role of attitudes and confidence towards ICT. In addition, the role of school and governmental leadership is identified as significant by Hramiak and Boulton (2013), while other studies consider the relationship between Web 2.0 usage, self-efficacy, perceived usefulness of the tool and core values to be highly relevant (Ertmer \& Ottenbreit-Leftwich, 2010; Tyagi, 2012). The large number of potentially influential factors indicates the scale of the challenge faced by primary school teachers and leaders in the effective integration and use of Web 2.0 resources. In addition, there are also other internal factors beyond personal beliefs about technology that may be influencing teachers' decisions to use or not to use ICT in their classrooms. One such factor is self-efficacy.

\section{Self-efficacy in the Education Setting}

Self-efficacy, as expressed by Bandura (1977 p. 36), is key to human action and agency. Building on his work into social learning theory, Bandura (1977) describes self-efficacy not as a fixed belief in one's abilities but rather one's changing cognitive, social, emotional and behavioral responses to situations. A person's belief in their ability is, according to Bandura (1997) key to being competent or successful at a task. Believing that one is able to achieve, impacts on one's ability to accomplish a goal.

In the context of educational technologies, a teacher's perceived level of self-efficacy, sometimes termed self-belief, can directly impact on their use of Web 2.0 resources thereby limiting what they can achieve. Self-efficacy, as expressed by Bandura (1997), is influenced by four key factors:

\section{Mastery Experiences \\ 2. Vicarious Experiences \\ 3. Verbal Persuasion \\ 4. Affective State}

According to Bandura's (1997) research, affective state can be influenced through the development of vicarious and mastery experiences and is not often materially changed by independent external forces (Bandura, 1997). It is therefore essential to provide mastery and vicarious experiences to teachers in order to develop their self-efficacy levels with Web 2.0 
resources. This creates a challenge for schools, as there are currently limited numbers of teachers or leaders available to provide their colleagues with these mastery and vicarious experiences.

While Web 2.0 resources are often declared as effective for learning (Baltzersen, 2010; Cheng, Lou, Khu, \& Shih, 2013) the practical challenges of providing positive experiences from which teachers might learn and develop their self-efficacy continues. This is apparent particularly in light of the lack of directly related research, either from within Australia or from primary schooling to inform teachers' (and leaders') choices. These shortages continue to challenge primary schools and individual teachers for whom there is limited primary school focused research to draw upon and only small pockets of Web 2.0 integration examples from which to learn. Further studies that connect practice to theoretical and pedagogical groundwork are clearly needed to support primary education and primary educators.

If we do not acknowledge the role of self-efficacy in the use of Web 2.0 in the classroom we risk a continuation of limited ICT integration in our schools. Bandura (2002 p. 10) reflected that, with the growth of technology, there is a need to acknowledge the impact of sociocultural factors impacting on its use. Not all members of society are enamored with, or have access to, technology. Bandura's directive has proven predictive, as we have now experienced a decade of growth in the amount and power of technology in schools but are seeing only minor changes in everyday educational practice. As Jimoyiannis et al. (2013, p. 249) identify:

"Existing literature, regarding the integration of ICT in schools, shows that despite governmental efforts and directives, the application of ICT in educational settings is rather peripheral acting, in most cases, as an 'add on' effect to regular teacher-centered classroom work."

Concurring with Bandura (2002), White (2008b) has remarked that we are yet to understand why any changes in educational use of ICT do occur, and what might be hindering the uptake of Web 2.0 in the classroom. White $(2008 a$, p. 11$)$ claims this is because existing research has often focused only on what is happening in classrooms rather than why any change is occurring. White (2008a) calls for more research focused on why we should use technology rather than focusing on specific ICT tools. This focus on the purpose of technology supports Bandura's concept of self-efficacy and the need for individuals to have meaningful experiences in order to develop their self-efficacy levels.

In order to understand how teachers' might be supported to understand how and why ICT can be used in the classroom (as noted by Ang \& Wang, 2006; Gregory \& Lloyd, 2010; Jimoyiannis et al., 2013; Martin \& Noakes, 2012) it would seem that we need more "user-centric research for the purpose of informing learning improvement" (White, 2008a, p. 5). In considering the personal factors of self-efficacy, beliefs, values and experiences, future research is needed focusing on the primary school teacher and the use of ICTs and Web 2.0 in the school context.

\section{External Factors Impacting on Teachers' Use of Web 2.0}

As well as personal beliefs and values, it is also necessary to consider individuals' contexts as well as their personal beliefs and values (Bandura, 2002). These contexts necessarily vary 
across schools, regions, districts and states, however several factors are highlighted as significant in promoting teachers' use of Web 2.0 in the classroom, these include providing teacher support, school leadership, access to resources and managing time constraints.

\section{Providing Teacher Support to Enhance ICT Integration}

The amount and type of support that leaders provide to teachers is important in enhancing teachers' use of Web 2.0 resources. In providing support to teachers, there appear to be two main types of support offered; either the provision of personalized pedagogical and ICT skillbased support as in Chee, Mehrotra, and Liu (2013) or the increase of access to ICT resources such as computers, tablets and wireless infrastructure (for example: Zhang \& Martinovic, 2008). Clearly, providing support for all teachers to learn and experience effective ICT use is critical for developing strong models of successful teaching with Web 2.0. These examples might then be used to support other teachers within and beyond their own school settings. In this way teachers' self-efficacy levels might be raised by providing further vicarious and mastery experiences to colleagues.

Providing the right type of support for teachers is a common theme in the literature, with varied approaches to teacher support highlighted. However, it appears that ensuring teachers feel supported is not an easy, or simple, task. In their study Zhang and Martinovic $(2008$, p. 8) declared there was "insufficient support" for teachers to learn how to integrate ICT into classrooms. This case study saw teachers gain new facilities and technology resources to support their professional learning but lacked leadership support, which led to a failure to sustain the changes. These teachers received support through infrastructure but not from their schools' leadership; it appears that both physical and cultural support is needed for innovations with Web 2.0 to succeed. To what degree this support should directly intervene in the classroom program, however, is not clear.

One model of teacher support for Web 2.0 integration appears to offer both infrastructure and personal support to teachers and demonstrated some success in affecting longer-term change in classroom practice. Chee et al. (2013) (with 42, 15 year old Singapore student participants) used online gaming (a Web 2.0 resource) to provide multi-faceted support to teachers. Although small in scale this study demonstrated positive outcomes for teachers and students through an holistic approach to teacher support that included physical resource provision, pedagogical modeling in classrooms, outside of class professional development and ongoing, on-demand, longer-term support from mentor teachers and technology experts.

Chee et al. (2013) focused significant attention on the professional development of the teacher, with researchers providing regular feedback and training for teachers (inside and outside the classroom) to support student-learning experiences. Chee et al. (2013, p. 24) refer to these in-depth teacher support practices as "handholding" and their data suggests that this type of focused, ongoing professional learning is necessary for the success of any technological or pedagogical program. This type of in-class, ongoing, teacher-focused support is limited in other research literature, and yet appears to have been highly effective here. More research is needed in this area to evaluate the effectiveness (and practicality) of this model of support, particularly within primary schools. 


\section{School Vision and ICT Use}

Beyond the role of leaders as supporters of teachers' Web 2.0 use, there are other ways in which school leaders might further support teachers' technology use. The literature emphasizes the need to develop and share a clear vision of technology use, for school leaders, teachers and the wider community. However, developing a school vision can be challenging when faced with existing beliefs and culture around the use of ICT. Dinham (2008, p. 138) notes that cultural change can take longer than anticipated as it requires participants to "go[ing] backwards", thereby, deconstructing an existing culture so that change can occur. In primary schools, existing cultures and practices around ICT use must be considered, reflected upon and potentially deconstructed before a new vision of ICT use and pedagogy can evolve and be supported. This is a key role of school leadership.

Developing a school vision is often referred to in the literature as an important factor in changing a school's culture or approach to learning (Dinham, 2008; Marzano, Water, \& McNulty, 2005; Senge et al., 2011). A major challenge remains however. Primary school leaders themselves require positive experiences to develop their own self-efficacy in using Web 2.0 resources effectively, so that they might be able to support their school communities in developing a vision of ICT use that is effective and appropriate for learning and teaching. Leaders are confronted with a lack of research that specifically reflects the primary school context.

\section{Technology Access}

As might be expected, access to computers and the Internet at school and at home also appear to impact on teachers' use of ICT and Web 2.0 in schools. Indeed, in considering the role of self-efficacy and the need for teachers to experience success with technology in a supportive setting, unreliable resources or hardware may prove challenging enough to limit a teachers attempts at Web 2.0 use. While sometimes seen as a technical role, it is important that school leaders work to ensure teachers' have stable and safe access to Web 2.0 resources, if they wish to see deeper and more effective use of Web 2.0 in the classroom.

Project Tomorrow $(2012 b)^{1}$ found that access to reliable equipment was a significant concern for teachers when transferring their university learning to a classroom setting. Project Tomorrow's (2012b) survey findings reflect the responses of university students training to become teachers. It is of concern therefore, that even before beginning their career these teachers are aware and wary of the lack of access to technology in schools. While it could be disputed that these judgments are assumptions made by those not yet fully engaged in the profession, it should be considered that these teacher candidates had taught in classrooms as part of their training and therefore do have some insight into the professional environment. Access to stable and useful technology is an essential part of Web 2.0 integration, although, as has been noted, it is not the only factor in successful technology use.

\footnotetext{
1 Speak Up Survey 2011 consisted of a sample of "330,117 K-12 students, 44,006 parents, 36,477 teachers, 2,025 librarians, 814 district administrators, and 3,319 school administrators representing 5,616 public and private schools from 1,250 districts." Project Tomorrow, 2012b, p. 2)
} 
In recent years within Australia, government programs and policies have focused on resource provision to enhance ICT access and use in schools. These include the National Broadband Network (NBN) (NBN Co Limited, 2012), the Digital Education Revolution Program (DER) (Department of Education Employment and Workplace Relations, 2011) and the Building Education Revolution program (BER) (National Building Education Revolution Coordinator, 2011). Over the past 4 years, these programs have seen every Year Nine student receive laptop-funding, access to increased bandwidth at home and at school, and new learning spaces within schools.

Jimoyiannis and Komis (2007) have reflected on whether this large-scale approach to resourcing schools impacts on teachers' use of technology in the classroom and on the learning experiences of our students. They ask whether, if technology resourcing were indeed the only impediment to pedagogical change, why educational outcomes and ICT use is not already improving around the world. The Digital Education Advisory Group (DEAG), tasked with reviewing the current state of technology use in Australian schools, states, "It is recommended that existing efforts to build teacher capacity and enhance school leadership be extended and accelerated as a matter of priority..." (Digital Education Advisory Group, 2013, p. 8).

Even with a range of online and digital tools provided to teachers in Victoria (Department of Education and Early Childhood Development, 2014), it would appear that many Australian teachers are not yet able or willing (or both) to integrate ICTs or Web 2.0 resources into their classrooms. Future research that investigates the role of the teacher in establishing technology access in the primary classroom may further inform these decisions.

\section{Time and ICT Use}

The need for sufficient, focused time for teachers to explore and learn about technology use and integration is a recurrent theme in the literature (for example: Chee et al., 2013; Zhao \& Frank, 2003). These studies indicate that insufficient time for teacher learning can lead to a lack of deep learning for teachers and limited use of Web 2.0 resources in the classroom.

In considering the role of time for teacher learning, Zhao and Frank (2003) compared the infiltration of technology into schools to the invasion of a foreign species into a natural ecosystem and remind us that significant time is needed for any substantial change to occur. Coates and Friedman (2009) also claim that time for teachers to learn and adapt is an imperative for improving technology use in schools. Indeed, Zhao and Frank (2003) indicate that providing time for teachers to explore new technology can lead to increased classroom use of ICT. To this end they suggest providing time for teachers to explore technology resources through a self-directed, discovery approach rather than through formal professional development training.

In opposition to the idea of time for pure exploration, Gray, Thompson, Sheard, Clerehan, and Hamilton (2010) have proposed that teachers should instead be offered structured opportunities to learn. Providing time for teachers' learning may be possible in schools, but there appears to be contradictory research on how best to use that time. Taking the middle ground with these approaches means that school leaders should endeavor to provide both unstructured and structured time for teachers to develop their skills with ICTs and Web 2.0 resources both before and during their work in the classroom. In providing these learning experiences, leaders must also maintain focus on the role of self-efficacy, personal beliefs and 
values. As has been noted previously, supporting teachers to make effective use of technology is multi-faceted and complex, and in the case of primary schooling, is lacking in available empirical evidence.

When one considers the disparate roles and tasks a teacher is called to undertake within their classroom the significance of providing time to develop skills and self-efficacy becomes clear. These roles and tasks include:

- Design ICT tasks that meet student needs (Chin, Sum, \& Foon, 2008)

- Support students to make connections within their learning (Drexler, 2010)

- Enable and support feedback and interaction online (Hall, 2009)

- Develop "autonomy, capability and creativity" in their students (Drexler, 2010, p. 114)

- Interact with other teachers beyond their classrooms and schools (Zhao \& Frank, 2003)

- Identify a clear purpose for their own and their students' learning (Higgins \& Russel, 2003)

- Make appropriate judgments for assessing the students' learning (Jenkinson, 2009)

For leaders to support the integration of technology, teachers' time must be used effectively and should acknowledge the expertise, confidence and self-efficacy levels of individual teachers. Learning must be ongoing, focused and purposeful (Chee et al., 2013; Donmoyer, 2000) and while Chee et al. (2013) provide one model of this kind of support, this does not appear to be widely used. Exactly what this support should look like for the wider primary school context, however, remains to be explored.

Having considered the internal (personal) and external (socio-cultural) factors to teachers use of technologies, the student himself will now be considered as a key stakeholder in the use of ICT for learning.

\section{Student Readiness for Web 2.0 Learning}

\section{Changes in Learning for Students}

McElvaney (2009, p. 8) sees today's students as "editors, creators, writers [and] critics" and argues, "The true quality and effectiveness [of online tools] ... depends on the learner him/herself". As such, it should be asked whether students are indeed ready for these changes to learning and whether they are comfortable or able to achieve success with the increased autonomy and self-direction required for effective learning with Web 2.0 resources.

\section{Student Expectations of Online Learning Environments}

There are an increasing number of free online Web 2.0 services that have proliferated in recent years. These tools appear to have impacted on students' expectations of the online tools they use at school as well as their own use of web-based resources at home. 
An example of these changing expectations is provided by Zixiu and Stevens (2011) who report an inverse correlation between familiarity with Facebook or MySpace and the perceived usefulness of the wiki used throughout their higher education course; the more familiar students were with social media, the less useful they found the course-provided wiki. This study of 205 higher education students found that personal experiences and interactions with online resources created an expectation of high level design, ease of use and open access (Zixiu \& Stevens, 2011).

These expectations, informed by personal experiences beyond the classroom, may indicate that a school's online learning environment requires a similar focus on design, ease of use and accessibility as the tools that are frequently used in students' daily lives. For example, Zixiu and Stevens (2007 p. 15) received feedback from their students that the wiki used for the course was "...quite rudimentary and not particularly user friendly..." as well as "being too plain...not as easy to use..." Students appear to expect a certain level of design and personalization in a Web 2.0 resource in order to engage fully with the learning experience.

Two decades ago, Goodhue and Thompson (1995) surveyed 600 adults in America, working in 2 separate businesses (one in transportation and one in insurance). Questions were asked about the ways in which employees used and chose technology for their professional lives. The findings indicated that when users of an ICT are involved in both the design and selection of the tool, they are more likely to use it and to feel more positive about its effectiveness. The study also indicated that when users are included in these choices the ICTs chosen are more likely to meet the desired outcomes (Goodhue \& Thompson, 1995, p. 230).

While the technologies available to businesses have changed significantly since the publishing of Goodhue and Thompson's paper, their findings, along with those of Zixiu and Stevens (2011), may signal an important challenge for primary education. Educators may find increased learning benefits and engagement for their students if they strive to involve students in the selection, set up and design of online learning environments. Experiencing student success and seeing purpose in Web 2.0 use may also impact positively on teachers' self-efficacy levels, supporting further learning, trialing and integration of these tools.

Primary school students however, by virtue of their age and experience, require more in-depth safety and skills training as well as supervision than their older counterparts. These challenges are not insurmountable but must be considered from the perspective of the primary school. Research into how best to include student voice in the choice and use of Web 2.0 with this younger age group, and thereby aim to meet their expectations of an online learning tool, requires further investigation.

\section{Inequality in Technology Access}

As has been seen, a growing number of students are engaging with Web 2.0 in their private lives (Australian Communications and Media Authority, 2013). Although educational use of technology continues to be varied, unequal access to ICTs is raised in the literature as another factor that teachers have to consider when making choices about technology. As Livingstone and Helsper (2007) identify, it is important for all students to have access to the online world. This may provide them with more opportunities for work beyond school and can expose them to a world beyond their everyday lives. Indeed Livingstone and Helsper (2007) claim that at- 
home Internet access can close the educational gap that may be created by a student's lower socio-economic status. Where at-home access to ICT is not possible, teachers in school settings are challenged to provide more access to, and experience with, ICT.

Livingstone and Helsper (2007, p. 692) go further and make specific age-based suggestions for the types of ICT use that should be provided by schools: "it appears that for younger children skills-based interventions would be optimal, while for older teens encouraging more frequent use will enhance the take-up of opportunities".

It is important to note this call for skills-based training for younger, primary school aged students in order to ensure that students might experience equity in access to ICTs and skills development. Not all students are able or willing to engage with technology at a high level and they may require further support to fully engage with online learning opportunities. In order for students to receive this support, teachers necessarily require learning experiences that relate to primary schooling. However, to meet students' needs, teacher self-efficacy levels must first be addressed. The role of the individual teacher again appears significant to the effective integration of Web 2.0 resources.

\section{Student Peer Interactions and ICT Use}

Students also appear to be influenced in their technology choices by the tools with which their peers are engaged. As friendships and peer groups become increasingly significant to children approaching their teenage years (Buhrmester, 1990) a consideration of others' use of technology may influence a student's readiness or willingness to engage fully with Web 2.0 tools for learning. What their peers may or may not be doing with technology may impact on what the social group as a whole will engage with, and thereby impact on the success or failure of Web 2.0 use in education. It appears that teachers' knowledge of the tools with which students are engaging outside of school may impact on the success of classroom programs using technology.

\section{Teacher Support for Student Use of Web 2.0}

With increased technology use for learning, teachers are asked to maintain a strong, supportive role in the classroom. Drexler $(2010$, p. 1) notes that "increased responsibility and control do not necessarily equate to learning motivation", indicating that students need more than access and free choice of Web 2.0 tools to learn effectively through technology.

As students move from passive receivers of information to active directors of their own learning (Drexler, 2010) they continue to need teacher support to go deeper with both ICT skills and the learning of content. Ongoing teacher support to facilitate deeper learning appears in the literature as a key challenge for ICT integration (Chen, 2009; Pow \& Fu, 2012) and reinforces the important role of teachers in classrooms. Requiring this kind of learning support again indicates that teachers need the necessary technical and pedagogical skills to support students' learning in their classrooms. 


\section{Personal Choice in Online Learning}

Pow and Fu (2012) identified that not all students are engaged with, or enjoy, the use of ICTs in the same ways. Indeed, teachers should never assume that all students are keen users and manipulators of technology. Pow and Fu's (2012), 42-student case study, demonstrated that engagement is a pre-requisite for successful learning with ICTs. While searching for the reasons for low participant numbers in their study they observed that a low level of engagement for learning in general led to lower motivation to learn through technology.

To counter this, Pow and Fu (2012) grouped students together for their blog-based learning activities, aiming to develop a sense of ownership over the online space. This had the effect, according to Pow and Fu (2012), of increasing students' "interest in learning" (Pow \& Fu, 2012, p. 4). A sense of ownership in educational online spaces, as noted previously, may offer a stronger "sense of responsibility" (Pow \& Fu, 2012, p. 4) for the Web 2.0 tools, similar to that which students profess to feel in their personal lives. The teacher, however, is again central to this sense of ownership as they direct the learning experiences of their students.

McElvaney (2009) argues this need to control the web is inherent in our everyday use of the online environment. There is an expectation that we are able to personalize our online experiences by choosing what we read and see and how, and with whom, we interact. Our students appear to expect this level of control and interaction with Web 2.0 resources for learning.

McElvaney's (2009) findings indicate that allowing personal choice with ICT is an important consideration and potential strategy for teachers. While allowing student choice with ICTs appears to be significant, it is the teacher who is central to these decisions, as lower levels of teacher self-efficacy may limit the amount of control they are willing to relinquish to their students (Bandura, 2002). It is clear that the teacher remains integral to learning with Web 2.0 resources, particularly in the primary school setting.

\section{Conclusion}

This paper has identified that teacher self-efficacy, beliefs and experiences significantly impact on the ways in which Web 2.0 resources (and ICTs more generally) are used in the classroom. The individual teacher would seem to have not only a significant impact on student learning (Hattie, 2009) but also to be rather resistant to change (Chen, 2008). This poses a challenge for both teachers and leaders in today's schools. Self-efficacy in particular has been highlighted as a key factor in the integration of ICT; the challenge for leaders who have limited access to models of success to support the growth of self-efficacy has also been considered.

Beyond the individual teacher, and sometimes out of their control, are several external factors that appear to be impacting on teachers' choices to use Web 2.0 resources in the classroom, these include: national and global education policies: limited access to reliable physical resources: the influence of school leadership: challenges of time for learning and exploring: and ensuring effective ongoing support for teachers.

This paper has considered students as fundamental stakeholders in the decisions teachers and leaders make about technology. Several factors have been discussed that may impact on 
students' engagement with Web 2.0 resources, including peer and social interactions, high expectations of online resources, requiring ongoing support from teachers, the role of personal choice when working online and acknowledging diverse student interests and experiences with technology.

Having identified a wide range of complex and interacting factors, it remains to be seen whether primary school teachers and their students interact and experience Web 2.0 resources in the same way as their older peers and colleagues working in secondary and tertiary education.

\section{Recommendations}

The range of factors identified in this paper offer a perspective on the use of technologies in primary education that focuses not on the tools themselves but rather on the role of teachers and students as key stakeholders.

With the goal of increasing effective use of Web 2.0 resources, this paper offers insight into the factors that influence the choices teachers make when faced with online tools. With limited research in the primary school area, this paper has discussed the use of online resources across a range of educational settings in order to explore what is currently known about how and why these tools are used for learning. Tentative connections have been made from these studies to the primary setting, acknowledging that each context is unique and each educational setting requires different interactions, considerations and learning approaches from learners and their teachers.

Having made these connections, four questions for future research are suggested:

- What is the impact of teacher self-efficacy levels on the use of Web 2.0 resources in primary schools?

- How might we best support primary school teachers to learn and explore the potential of Web 2.0?

- How can school leaders best support primary school teachers to use Web 2.0 resources?

- What should the role of primary students be in choosing and using Web 2.0?

With so many hurdles to successful ICT integration identified within the literature, it is important to note that there also exist pockets of relevant research within the literature body. Although most often at secondary school level, examples can be found of ICT and Web 2.0 resources used to enhance student-learning outcomes in school settings. The case studies demonstrate the potential of these resources to enhance student learning. These teachers and researchers often appear to be working alone, in small teams or within focused in-house programs that do not extend beyond the single school.

Clearly there exists an opportunity for learning from these smaller studies, and to investigate the transferability of the approaches used to more general primary school settings. Further research that focuses on the use of Web 2.0 in the primary school classroom by the primary school student and their teachers is needed before we can see these learning tools used to their full potential. 


\section{References}

Alexander, B. \& Levine, A. (2008). Web 2.0 storytelling: Emergence of a new genre. EDUCAUSE Review, 43(6), 40-56.

Ang, K. H., \& Wang, Q. (2006). A case study of engaging primary school students in learning science by using Active Worlds. Proceedings of the first International LAMS Conference 2006: Designing the future of learning. Sydney, 6-8 December.

Apple, M. (2010). Chapter 1: Global crises, social justice, and education. In M. W. Apple (Ed.), Global Crises, Social Justice, and Education (pp. 25). London: Routledge.

Australian Communications and Media Authority. (2013). Like, post, share: Young Australians' experience of social media. Canberra: Newspoll.

Australian Curriculum: Overview General Capabilities (2014). Retrieved 30 October, 2014, from http://www.australiancurriculum.edu.au/technologies/general-capabilities

Baltzersen, R. (2010). Radical transparency: Open access as a key concept in wiki pedagogy. Australasian Journal of Educational Technology, 26(6), 791-809.

Bandura, A. (1997). Self-efficacy: The exercise of control. New York: W. H. Freeman \& Company.

Bandura, A. (2002). Growing primacy of human agency in adaptation and change in the electronic era. European Psychologist, 7(1), 2.

Bandura, A., \& McClelland, D. C. (1977). Social learning theory. New York: General Learning Press.

Buhrmester, D. (1990). Intimacy of Friendship, Interpersonal Competence, and Adjustment during Preadolescence and Adolescence. Child Development, 61(4), 1101-1111.

Chee, Y. S., Mehrotra, S., \& Liu, Q. (2013). Effective game-based citizenship education in the age of new media. Electronic Journal of e-Learning, 11(1), 16-28.

Chen. (2009). Personalized E-learning system with self-regulated learning assisted mechanisms for promoting learning performance. Expert Systems with Applications, 36(5), 88168829 .

Cheng, Y., Lou, S., Khu, S., \& Shih, R. (2013). Investigating elementary school student's technology acceptance by applying digital game-based learning to environmental education.

Chin, W., Sum, C., \& Foon, H. (2008). Exploring Singapore primary school students' perceptions of Chinese asynchronous online discussions. New Horizons in Education, 56, 1013.

Clandinin, D. J. \& Connelly, F. M. (1996). Teachers' professional knowledge landscapes: Teacher stories - stories of teachers -school stories - stories of schools. Educational Researcher, 25(3), 24-30.

Coates, H. \& Friedman, T. (2009). School connections: using ICT to engage students in learning A collaboration between Microsoft, NSW DET, dk2 and ACER: Microsoft Partners in Learning.

Collins, R. (2010). Technology and schools : Where are we going? Teacher, 209, 44-47. 
Communications Division for Flagship Strategies Division. (2012). Towards Victoria as a learning community. Melbourne: NEALS.

Crook, Cummings, J., Fisher, T., Graber, R., Harrison, C., Lewin, C., .. Sharples, M. (2008). Web 2.0 technologies for learning: The current landscape-opportunities, challenges and tensions Leading Next Generation Learning. Notthingham, UK: BECTA.

Department of Education and Early Childhood Development. (2014). Welcome to the school technology (eduSTAR) site. Retrieved on 30 October 2014 from http://www.edustar.vic. edu.au/

Department of Education Employment and Workplace Relations. (2011). Experience the Digital Education Revolution: National Secondary School Computer Fund. Retrieved on 12 September 2012 from http://www.deewr.gov.au/Schooling/DigitalEducationRevolution/ ComputerFund/Pages/NationalSecondarySchoolComputerFundOverview.aspx

Digital Education Advisory Group. (2013). Beyond the classroom: A new digital education for young Australians in the 21st century. Retrieved on 8 May 2015 from http://deewr.gov. au/digital-education-advisory-group-report

Dinham, S. (2008). How to get your school moving and improving (1 ed.). Camberwell, Victoria, Australia: ACER Press.

Doherty, I. (2011). Evaluating the impact of educational technology professional development upon adoption of Web 2.0 tools in teaching. Australasian Journal of Educational Technology, 27(3), 381-396.

Donmoyer, R. (2000). Generalizability and the single-case study. In R. Gomm, M. Hammersley, \& P. Foster (Eds.), Case study method: Key issues, key texts. London: Sage.

Drexler, W. (2010). The networked student model for construction of personal learning environments: Balancing teacher control and student autonomy. Australasian Journal of Educational Technology, 26(3), 369-385.

Ertmer, P. \& Ottenbreit-Leftwich, A. (2010). Teacher technology change: How knowledge, confidence, beliefs, and culture intersect. Journal of Research on Technology in Education, 42(3), 255-284.

Fu, J. (2013). Complexity of ICT in education: A critical literature review and its implications. International Journal of Education and Development using Information and Communication Technology, 9(1), 112-125.

Goodhue, D. \& Thompson, R. (1995). Task-technology fit and individual performance. MIS Quarterly, 19(2), 213-236.

Gray, K., Thompson, C., Sheard, J., Clerehan, R., \& Hamilton, M. (2010). Students as Web 2.0 authors: Implications for assessment design and conduct. Australasian Journal of Educational Technology, 26(1), 105-122.

Gregory, S. \& Lloyd, I. (2010). Accepting choices: To ICT or not to ICT - Engagement. In D. Gronn \& G. Romeo (Eds.), ACEC2010: Digital diversity. Proceedings of the Australian Computers in Education Conference 2010. Carlton, Victoria: Australian Council for Computers in Education (ACEC). Retrieved on 8 May 2015 from http://acec2010.acce.edu.au/proposal /476/accepting-choices-ict-or-not-ict-engagement.

Hall, R. (2009). Towards a fusion of rormal and informal learning environments: The impact of the read/write web. Electronic Journal of e-Learning, 7(1), 29-40. 
Hattie, J. (2009). Visible Learning: A synthesis of over 800 meta-analyses relating to achievement. Oxford, UK: Routledge.

Higgins, J., \& Russel, M. (2003). USEIT: Report 6:Teachers' beliefs about technology and instruction. In K. O'Connor (Ed.). Boston, MA: Boston College, Technology and Assessment Study Collaborative.

Hramiak, A. \& Boulton, H. (2013). Escalating the use of Web 2.0 technology in secondary schools in the United Kingdom: Barriers and enablers beyond teacher training. Electronic Journal of e-Learning, 11(2), 91-100.

Jenkinson, J. (2009). Measuring the effectiveness of educational technology. Electronic Journal of e-Learning, 7(3), 273-280.

Jimoyiannis, A., Tsiotakis, P., Roussinos, D., \& Siorenta, A. (2013). Preparing teachers to integrate Web 2.0 in school practice: Toward a framework for Pedagogy 2.0. Australasian Journal of Educational Technology, 29(2), 248-267.

Kay, R., \& Knaack, L. (2008). Exploring the impact of learning objects in middle school mathematics and science classrooms: A formative analysis. Canadian Journal of Learning and Technology, 34(1). Retrieved on 8 May 2015 from http://www.cjlt.ca/index.php/ /article/view/174

Lincoln, Y. S. \& Guba, E. G. (1985). Naturalistic inquiry. Newbury Park, CA: Sage.

Livingstone, S. \& Helsper, E. (2007). Gradations in digital inclusions: children, young people and the digital divide. New Media \& Society, 9(4), 671-696.

Martin, M. \& Noakes, M. (2012). Fostering a web 2.0 ethos in a traditional-learning environment. The Electronic Journal of e-Learning, 10(3), 284-292.

Marzano, R., Water, T., \& McNulty, B. (2005). School leadership that works. Denver, CO: ASCD.

McElvaney, J. (2009). Weaving a Personal Web: Using online technologies to create customised, connected and dynamic learning environments. Canadian Journal of Learning and Technology,35(2). Retrieved on 8 May 2015 from http://www.cjlt.ca index.php/cjlt/issue/view/68

Means, B., Toyama, Y., Murphy, R., Bakia, M., \& Jones, K. (2009). Evaluation of evidence-based practices in online learning; A meta-analysis and review of online learning studies. Washington, DC: US Department of Education Office of Planning, Evaluation, and Policy Development.

Ministerial Council on Education Employment Training and Youth Affairs. (2008). Melbourne Declaration on Educational Goals for Young Australians.

National Building Education Revolution Coordinator. (2011). Building the education revolution guidelines. Canberra.

NBN Co Limited. (2012). NBN for home: Education case studies. Retrieved on 1 July 2013 from http://www.nbnco.com.au/nbn-for-home/education-case-studies.html

Patton, M. Q. (2001). Qualitative research \& evaluation methods ( $3^{\text {rd }}$ ed.). London: Sage.

Pow, J. \& Fu, J. (2012). Developing Digital Literacy through Collaborative Inquiry Learning in the Web 2.0 Environment - An Exploration of Implementing Strategy. Journal of Information Technology Education: Research, 11, 287-299. 
Project Tomorrow. (2012b). learning in the 21st century: Digital experiences and expectations of tomorrow's teachers selected national findings of the speakup 2010 survey. Washington, DC: Speak Up.

Sang, G., Valcke, M., Van Braak, J., \& Tondeur, J. (2010). Student teachers' thinking processes and ICT integration: Predictors of prospective teaching behaviors with educational technology. Computers \& Education, 54(1), 103-112.

Senge, P., McCabe, N., Lucas, T., Kleiner, A., Dutton, J., \& Smith, B. (2011). Schools that Learn: a fifth discipline fieldbook for educators, parents and everyone who cares about education. New York: Crown Business.

Tyagi, S. (2012). Adoption of Web 2.0 technology in higher education: A case study of universities in the National Capital Region, India. International Journal of Education and Development using Information and Communication Technology, 8(2), 28-43.

White, G. (2008a). Digital learning: An Australian research agenda. Digital Learning Research, 3. Retrieved on 8 May 2015 from http://linkresearchlab.org/dlrn/

White, G. (2008b). ICT Trends in education. Digital Learning Research, 2. Retrieved on 10 July 2015 from http://linkresearchlab.org/dlrn/

Zhang, Z., \& Martinovic, D. (2008). ICT in teacher education: Examining needs, expectations and attitudes. Canadian Journal of Learning and Technology, 34(2). Retrieved on 8 May 2015 from http://www.cjlt.ca/index.php/cjlt/article/view/498/229

Zhao, Y. \& Frank, K. (2003). Factors affecting technology uses in schools: An ecological perspective. American Educational Research Journal, 40(4), 807-840.

Zixiu, G. \& Stevens, K. J. (2011). Factors influencing perceived usefulness of wikis for group collaborative learning by first year students. Australasian Journal of Educational Technology, 27(2), 221-242.

Correspondence: Joanne Blannin, Doctor of Education Candidate, Melbourne Graduate School of Education, The University of Melbourne, Parkville, Victoria, Australia. 